\title{
A zona de sombra dos conceitos de agenda-setting e gatekeeper
}

\author{
Beatriz Marocco
}

\begin{abstract}
Resumo
Este artigo explora a produção de scholars americanos e alemães como Albert Schäffle (1831-1903); Karl Knies (1821-1898); Karl Bücher (1847-1930); Ferdinand Tönnies (1835-1936); Albion Small (1854-1926); Edward Ross (1856-1951); Max Weber (1864-1920); Robert Park (1864-1944) and Walter Lippmann (1889-1974). Recupera essas epistemes exógenas situando-as no interior do quadro dos diferentes limiares que caracterizam a constituição do pensamento jornalistico (Foucault, 1995) para visibilizá-las em sua exterioridade original mesma e, com o seu deslocamento ao presente, ilumina a zona de sombra que ocupam nos conceitos contemporâneos das teorias do jornalismo como agenda-setting e gatekeeper.
\end{abstract}

Palavras-chave: jornalismo, teorias sociais da imprensa, agendasetting,gatekeeper.

\begin{abstract}
This article aims at exploring the theoretical production that approximates German and American scholars such as Albert Schäffle (1831-1903); Karl Knies (1827-189s); Karl Bücher (184-1930); Ferdinand Tönnies (1835.1936); Albion Small (185t-1926); Edward Ross (1856-1951); Max Weber (186t-1920); Robert Park (1864-1944) and Walter Lippmann (1889-1971), recovering them, in their importance, from the pre-history of the press studies 10 materialize its emergency in the concepts of the contemporany theories of journalism, like agenda-setting and gatekeeper. Positioned in a gap in the press studies, it takes as a starting point, the foucaultian descrintion of the different thresholds that established the levels of discourse elaboration (Foucault, 1995).
\end{abstract}

Keywords: journalism, social theories of the press, agenda-setting. gatekeeper.

\footnotetext{
- Jornalista, professora, pesquisadora da Unisinos. Doutora em Jornalismo/Comunicacăo. Universidade Autónoma de Barcelona/UFRGS. Artigo escrito com a colaboraçāo da bolsista Unibic de Iniciaçāo Científica Maria Càndida Lucca di Primio.
} 
Este texto ${ }^{1}$ pretende seguir as pistas dos primeiros pensadores do jornalismo, resgatá-los do sono em que se encontram e, com isso, iluminar a zona de sombra que ocupam nas teorias contemporâneas do jornalismo. Para tanto, desde uma perspectiva foucaultiana, esboça o quadro em que poderiam estar inscritos, na vizinhança dos diferentes limiares históricos que marcam a constituição do pensamento jornalístico para, finalmente, neste amplo contexto, descrever como algumas palavras ancestrais que lhes correspondem foram sendo deslocadas vagarosamente, ao longo de mais de um século, desde a sua emergência nessas epistemes exógenas, no final do século XIX, até os novos sentidos que apresentam no bojo de conceitos do jornalismo contemporâneo. Nesta extensa franja de tempo, é possível identificar como algumas idéias apareceram no seio da sociologia, da filosofia e da economia, em um jogo entre disciplinas, quando não se havia constituído ainda o campo do jornalismo, transformaram-se, como foram sendo purificadas até atingir as normas de cientificidade do campo jornalístico.

Nos inspira, primeiramente, a perspectiva de que o jornalismo pode ser compreendido historicamente e descrito no interior de um grande quadro com base nas transformações que sofre e nos diferentes limiares que transpõe. Em $A$ arqueologia do saber, Foucault estabelece quatro limiares, ou quatro emergências distintas de uma ciência, que podem ser aplicadas parcialmente ao discurso jornalístico, quer seja às condições da época em que se forjou como uma manifestação da indústria cultural e do capitalismo moderno, quer seja à sua condição de disciplina de status e pretensão científica.

a) limiar de positividade: momento em que uma determinada prática discursiva é identificada como sendo jornalismo estritamente por seus vínculos com o desenvolvimento das técnicas de reprodução rápida (e as noções de tempo e espaço que este configura) e com as funções político-econômicas que se lhe atribuía na sociedade burguesa. Pode-se situar neste período os discursos que ecoavam dos relatos burocráticos da administração pública ou das práticas de guerra e que apareceram nos jornais brasileiros publicados em meados do século XIX (Marocco, 2004).

b) limiar de epistemologização: quando um conjunto de normas confere regularidade ao discurso, ou seja, pretende a autonomia do discurso jornalístico do discurso das administrações públicas, dos partidos políticos e/ou literário e sua vinculação a um modelo propriamente jornalístico, podese dizer que esse transpôs um limiar de epistemologização. Foucault chamará "episteme" ao aspecto de profundidade dos saberes, quer se trate de saberes de uma forma mais completa, quer se trate de algo de outra ordem, como as estruturas econômicas ou sociais das quais o saber seria somente a sua expressão ou a sua projeção. A "episteme" se opõe ao nível das opiniões, é 
anterior ao ordenamento do discurso efetuado pela ciência e, independentemente desse, constitui uma ordem específica dos discursos que em uma determinada época lhe confere uma certa regularidade. Assim, tomando por base o que foi publicado entre final do século XIX e meados do século passado em jornais brasileiros (Marocco, 2004) é possível constatar que o que tornou o discurso jornalístico possível na época foi. de um lado. uma homogeneidade técnica e enunciativa que se manifesta em uma base globalizada de jornais, e, de outro, as suas relações com uma rede de instituições que compartilhavam o projeto reformista dos governos e pretendiam o controle social. Poder-se-ia localizar neste momento, igualmente, uma jdiossincrasia do saber jomalístico: a coexistência dos discursos produzidos pelos jornais com as "teorias sociais da imprensa" (H. Hardt, 1979). Há entre o jornal e esse conjunto de teorias uma relação surda e à distância que emerge nas pistas encontradas em discursos jornalísticos que fazem eco da cruzada reformista dos estados nacionais, embora o que se fazia presente, muitas vezes, nessas epistemes exógenas, condenasse o modo de objetivação jornalística dos acontecimentos, ou seja. certas idéias eram compartilhadas por uns e outros, mas não havia uma interferência das teorias sobre as práticas jornalísticas; simultaneamente às críticas desse grupo de intelectuais sobre a mecânica jornalística e os seus efeitos, os discursos continuavam sendo produzidos aos milhares. Nada parecia abalar o edifício do jornal e o sistema de agendamento jomalístico comprometido ora com as "vacas sagradas" (E. Ross, em Reis, 1994, p. 198-199) - empresas, o sistema fiscal e o sistema de partidos políticos -, veneradas pela imprensa norteamericana - ora com os projetos reformistas dos governos (Marocco, 2004). A força crítica dos teóricos em relação às práticas jornalísticas era nenhuma, e o poder que tinham, em relação ao crescente poder dos jornais, merecia a desconfiança dos próprios críticos. ¿QQué puede hacerse respecto de la supresión de las noticias?', perguntava-se Ross. E era ele mesmo quem respondia: 'Al menos podemos desistir de criticar y predicar. Urgir al director, sometido al anunciante o al propietario, a ser más independiente es invitarle a que abandone la profesión. En cuando al capitalista propietario, exhortarlo para que maneje su diario en interés de la verdad y del progreso es tan razonable como tratar de convencer al molinero para que maneje su propiedad en favor del bien general en lugar de en su beneficio privado. Lo que hace falta es abrir un camino nuevo y amplio para la conciencia pública' (E. Ross. em Reis, 1994, p. 200).

c) limiar de cientificidade: quando o jornalismo consolida um conjunto de práticas regulamentadas e regulamentadoras e ganha um espaço na academia, poder-se-ia dizer que transpõe o limiar de cientificidade. Esta liberação epistemológica, que dará conta de sua face institucional e de sua 
face discursiva vinha se esboçando lentamente através de epistemes exógenas. Os discursos publicados nos jornais indicam que, ao nível das práticas, igualmente se ensaiava a ruptura entre jornalismo e literatura desde o período anterior. Lima Barreto nos ajuda a compreender o que ocorria. Segundo escreve, naquele tempo 'todos os repórteres e burocratas dos jornais demonstravam desprezo pela literatura e pelos literatos, mas apesar da vontade concreta de estabelecer um campo autônomo, copiavam os processos dos jornalistas, as frases dos poetas, deturpavam os conceitos dos historiadores, imitando o seu estilo com uma "habilidade simiesca" (1956, p. 122).

Os discursos eram marcados por uma "pretensão de objetividade" e de autonomia da literatura que, normalmente, não se materializava nos textos. Mais tarde, a intenção irá desaguar no bojo de duas noções: 1. "objetividade jornalística". A noção de objetividade regulamentará as práticas e fortalecerá uma densa arquitetura teórica de teor funcionalista com os elementos necessários à construção e funcionamento de um modelo de texto informativo e propriamente jornalístico; e 2. "gêneros jornalísticos". Os gêneros artificiarão o distanciamento e os matizes existentes entre notícia e comentário. Objetividade e gêneros devem contribuir para que o jornalismo tenha a sua autonomia e se autonomize em relação a outras áreas, como a literatura, a filosofia, a economia e a política. Devem, portanto, deixar para trás uma formação discursiva forjada no rastro do capitalismo e do desenvolvimento tecnológico, que se dava a conhecer graças às técnicas da tipografia, muitas vezes no próprio espaço das tipografias, e às regras emprestadas da retórica, da administração pública, da literatura, da jurisprudência, dos negócios e da política. As práticas tomarão para si um conjunto de procedimentos que as afastará dos outros saberes e da natureza capitalista do jornal; essas normas e modelos possibilitarão um afastamento relativo na medida que reconhecem a diferença entre jornalismo e publicidade e exercem uma função dominante sobre o saber jornalístico: a função de informar. Posteriormente, um sem-fim de teorias fará avançar os estudos sobre os processos que revelarão as práticas jornalísticas em sua exterioridade: agenda-setting e gatekeeper vão aprofundar as leis de construção do discurso jornalístico agora não apenas em relação à linguagem e à sua necessidade de autonomia, mas em relação ao poder do jornalismo de seleção e produção dos acontecimento e à sua repercussão sobre a ordem social.

d) limiar de formalização: corresponde ao momento em que uma formação discursiva se estrutura como um edifício formal definido pelos 'axiomas que lhe são necessários, os elementos que usa, as estruturas proposicionais que the são legítimas e as transformações que aceita' para poder, com tudo isso, desenvolver, a partir de si mesmo, um "discurso científico" (Foucault, 1995, p. 211). Seguramente o jornalismo não é um 
conhecimento formal: não atinge o nível de rigor que se pode esperar, por exemplo, da física, da matemática, da química, tampouco há como escapar de sua vinculação inexorável ao curso real dos acontecimentos e substituí-la por abstrações em que uma ordem lógica conceitual torne inteligível a ordem real, quando muito o jornalismo poderá reconhecer-se, em outro nível, que o aproxima das ciências humanas e sociais, ora como um seu espelho ora, como o fazem certas vertentes mais contemporâneas do pensamento jornalístico, como um nível de produção dos acontecimentos da realidade; ao mesmo tempo, o pensamento jornalístico apoiado nas vertentes de produção acadêmica e com pretensão de cientificidade comporta um acúmulo, apenas organizado, de observações empíricas, de tentativas e de resultados brutos, de prescrições profissionais e reflexões teóricas e de dependência conceptual ou metodológica de outras disciplinas: encontramo-lo, igualmente. em ambas formas cerceado por umas leis de mercado e regulamentações institucionais.

\section{A função enunciativa}

Isto posto, gostaríamos de ativar a formação de um campo de forças magnético, um 'campo de exercício da função enunciativa', que, nos termos do arquivo foucaultiano, poderá aproximar em um tempo, que não é o seu próprio tempo histórico, os diferentes discursos que configuraram as práticas jornalísticas em dois diferentes limiares - epistemologização e cientificidade - demonstrando, por exemplo, como os discursos pronunciados ao longo de dois séculos se aproximam, sua eventual coincidência e as condições nas quais alternadamente se instauram. Para realizar estas conexões, Foucault esboça a figura do enunciado e a função enunciativa (Foucault. 1995. p. 144146).

Em seu sentido foucaultiano, o enunciado está 'ligado não apenas a situações que o provocam e a consequiências por ele ocasionadas, mas, ao mesmo tempo, e segundo uma modalidade inteiramente diferente, a enunciados que o precedem e o seguem', nos diferentes grupos de discursos onde funciona (1995, p. 32). Enquanto o nivel gramatical, com a organização formal que resulta, não necessita mais que elementos e regras para combinar unidades em frases, o nível enunciativo apoia-se na função enunciativa para formar 'unidades igualmente abstratas e problemáticas' na extensão de umá curva, imaginada por G. Deleuze, 'que une pontos singulares, que efetua ou atualiza relações de força' (Foucault, 1995, p. 89; G. Deleuze, 1987, p. 108).

Deleuze reconhece a complexidade do enunciado em seu sentido foucaultiano a ponto de compará-lo ao sono. Os enunciados de Foucault, disse, são como o sono: cada um tem o seu objeto próprio ou se rodeia de um mundo (1987, p. 34). É necessário segui-los, parece responder-lhe Foucault, ao longo do seu sono, recolher 'os temas relacionados ao sono, ao esquecimento, à origem perdida', e procurar 'que modo de existência pode 
caracterizar os enunciados, independentemente de sua enunciação, na espessura do tempo em que subsistem, em que se conservaram' (1995, p. 142). Em outro momento de Foucault, Deleuze define o enunciado como 'uma multiplicidade, que atravessa os níveis, que cruza um domínio de estruturas antes de aparecer em formas concretas' e pelas mãos do analista (1987, p. 41).

É inútil, disse Foucault, 'procurar o enunciado junto aos grupamentos unitários de signos. Nem sintagma, nem regra de construção, nem forma canônica de sucessão e de permutação, mas sim o que faz com que existam tais conjuntos de signos, e permite que essas regras e essas formas se atualizem'. Foucault segue descrevendo os enunciados com uma série de negações. Não são como o ar que respiramos. Não são transparentes, são raros. Não estão escondidos, o que não significa que sejam visíveis. Não estão habitados pela presença secreta do que não foi dito, das significações ocultas. Não são o mesmo que o 'reprimido. Não se oferecem à percepção; é preciso certa mudança no olhar e na atitude para poder reconhecê-los e considerá-los em si mesmos (1995, p. 100).

Tal dinâmica rompe com a continuidade que dá consistência a uma certa concepção linear de avanço e conecta, simultaneamente, a existência de um enunciado a um discurso, ao saber a que pertence e a uma rede aberta e interligada de diferentes discursos, o que nos permite identificá-lo imediatamente como elemento de um sistema com certo grau de organização, independentemente de seu autor ou de quando foi pronunciado. Ao invés de recolher as familiaridades gramaticais quase perceptíveis entre as palavras e as coisas, o enunciado pode estabelecer relações entre as coisas ditas, não mais em uma "linearidade sem ruptura", mas sim em "figuras distintas", que se compõem umas com as outras segundo "relações múltiplas" (Foucault, 1995, p. 149).

Nos termos desse outro modo de analisar os discursos, intuímos que, sobretudo, o nosso trabalho será tirar da inércia "sistemas de enunciados" para que as coisas que foram ditas e que não foram devidamente reconhecidas não sigam amontoadas 'indefinidamente em uma multidão amorfa', mas se agrupem, se componham umas com as outras no presente em uma estranha rede que não havia sido imaginada por seus "autores" no momento em que foram articuladas textualmente (Foucault, 1995, p. 149).

Mais concretamente neste texto exploramos um conjunto de enunciados retirados de artigos, livros e jornais publicados durante o final do século XIX até o final do século XX por teóricos e jornalistas que falam sobre os acontecimentos que passam na realidade, as relações de poder entre jornalismo e sociedade desde fora ou, posteriormente, no interior do campo do jornalismo, e que, no sistema do arquivo, participam das relações enunciativas que, à revelia do que foi dito no interior de um domínio, de seu espaço e seu tempo, poderá ir além do que está escrito. Ao analista caberá, portanto, provocar relações entre o que aparentemente estava separado no passado, seguir as 
pistas de seu retorno silencioso, repetido e purificado, nas teorias contemporâneas, sob a forma dos conceitos de agenda setting e gatekeeper.

\section{A formação dos conceitos}

Um século separa o que foi dito sobre o jornalismo no seio de um conjunto de epistemes exógenas ${ }^{\mathfrak{t}}$ da cristalização dos conceitos de agendasetting e gatekeeper. Nas condições de possibilidade do arquivo foucaultiano, entretanto, é possívei aproximar esses dois limiares (epistemologização e cientificidade) nas relações que podem ser engendradas em torno do poder do jornalismo e do jornalista de configurar certas coisas que passam na realidade, fixar uma agenda e o impacto que isso pode vir a provocar sobre a sociedade ou, o que parece ser o mesmo em outras palavras, como uns e outros tentam explicar o papel e a função do jornalista e do jornal na sociedade, como o jornal/jornalista filtra, produz e define os acontecimentos a que nós prestamos atenção, filtra e define com o que nos importamos, determina que juízos estariam associados a esses acontecimentos e, por fim. como o jornal poderá influenciar o comportamento social, que efeitos de poder a agenda jornalística poderá provocar sobre a agenda social e vice-versa. Sob esse amplo espectro de atributos, funções e efeitos do jornal, do jornalismo e do jornalista, reconhecidos em diferentes teorias, habitam os enunciados que historicamente foram o espaço privilegiado e o veículo de duas singularidades do poder do jornalismo e de um efeito de poder do mesmo, ora situadas na esfera da produção jornalística (as duas primeiras), ora deslocado (o efeito) à esfera da recepção e da sociedade (Traquina, 2000. p. 19). São elas: 1. Configurar o que é e o que não é notícia; e 2. Configurar uma ordem jornalística da realidade. Por efeito de poder vem sendo mencionada, com maior ou menor certeza por diferentes pensadores, a possibilidade de o jornalismo ser um instrumento de controle social, direta ou indiretamente (two step flow), ou a possibilidade de gerar impacto no cotidiano das pessoas expostas às notícias.

\section{$O$ agendamento}

O conceito de agendamento inscreve-se no filão da teoria dos efeitos limitados inaugurada pelo modelo da comunicação em dois níveis (two step flow of communication) de Lazarsfeld; originalmente dá conta das práticas jornalísticas de "reprodução imperfeita" do que é importante no mundo político e, igualmente, sobre o que essa agenda jornalística configura pode ser partilhado com o público. O conceito foi esboçado por Cohen $(1963)^{7}$ mas é no artigo "The Agenda-setting function of mass media", que McCombs e Shaw (1972) vão atribuir essa expressão à hipótese de que as mídias ${ }^{8}$ podem muito bem determinar quais são as questões importantes de uma campanha política, ou seja, que as mídias podem estabelecer a "agenda" da campanha. Neste sentido, materializam o poder de agendamento de certos acontecimentos 
e de reprodução de um certo mundo político. Ao divulgarem o que os candidatos vão afirmando durante uma campanha, as mídias manifestam, igualmente, a organização do trabalho jornalístico, os processos de produção e seleção que supõem e a taxonomia jornalística a que dão origem: excluem, incluem, fornecem indícios (a partir da quantidade de informação e da posição por ela ocupada) sobre quais são as questões mais e quais são as questões menos importantes. Mas os autores são mais reticentes quando se trata de avaliar o impacto das mídias na opinião dos votantes: 'As provas deste estudo de que os eleitores tendem a partilhar a definição composta nas mídias acerca do que é importante, sugerem fortemente uma função de agendamento das mídias' (McCombs e Shaw, citados em N. Traquina, 2000, p. 17). Nesse aspecto, o estudo com uma amostra de eleitores de Chapel Hill não passou de um "primeiro teste" da hipótese do poder das mídias de definir a agenda pública. Mais de 20 anos depois, fazendo um balanço das novas investigações sobre agendamento, McCombs e Shaw (1993) apoiaram-se novamente em Cohen, mas desta vez para virar a clássica síntese de Cohen do avesso, afirmando que 'as mídias não só nos dizem em que pensar, mas também como pensar nisso, e consequentemente o que pensar'.

\section{Gatekeeper}

$\mathrm{Na}$ esfera da produção jornalística, as figuras dos gates (portões) e dos gatekeepers (jornalistas) que David Manning White elaborou em 1950 em artigo publicado na revista Journalism Quarterly, dão conta do processo de seleção das notícias. White observou, acompanhando as práticas de um jornalista, que as notícias passam por uma série de portões que são os momentos de decisão em relação aos quais o jornalista deve escolher o que será publicado. Mr. Gates, como chamou-o White, vivia e trabalhava há 25 anos em um jornal de uma cidade de 100 mil habitantes do meio oeste americano. Sua função: selecionar entre o grande volume de despachos das agências de notícias que chegavam diariamente aquelas notícias que o jornal publicaria no outro dia. A seleção, segundo White, seguia critérios subjetivos. Em seu livro de anotações, o jornalista classificava o material rejeitado como "demasiado vago" (26 notícias foram rejeitadas por esse motivo), ou como "composição aborrecida" (51), ou "sem interesse" (61).

O processo de seleção é subjetivo e arbitrário, com as decisões dependendo muito de juízos de valor baseados no conjunto de experiências, atitudes e expectativas do gatekeeper (White, 1993, p.149).

Warren Breed (1993) alargou a perspectiva do gatekeeper. Ele estudou o controle social nas redações, analisando os mecanismos de manutenção da linha editorial e política dos jornais. O autor observou que 'o jornalista conforma-se com as normas da política editorial da organização independente de qualquer idéia que ele tenha trazido consigo'. Breed (1993, p. 157-161) 
apresentou seis motivos que 'fazem com que o jornalista se conforme com a política editorial da organização: a autoridade institucional e as sanções: os sentimentos de dever e estima para com os superiores; as aspirações à mobilidade profissional; a ausência de fidelidade de grupo contrapropostas; o caráter agradável do trabalho; o fato de a notícia ser transformada em valor'. Na sua atividade diária, explica o autor, 'o jornalista redefine seus valores ao nível mais pragmático da redação' (Breed, 1993, p.157-161). Os estudos posteriores consideram a necessidade de integrar o papel do jornalista à análise das rotinas produtivas e da organização burocrática do jornal, ou seja, deslocam o processo de seleção da manipulação explícita da informação para a hipótese de uma distorção inconsciente, que pode ocorrer na cobertura jornalística (Wolf, 1994, p.166).

Molotch e Lester (1974, citados em Traquina, 2000) vão flexibilizar a noticiabilidade da esfera de decisão do jornalista para outras esferas da sociedade e, mais concretamente, para três tipos de pessoas (news assemblers, news promotors, e news consumers) que serão relacionadas posteriormente. no esquema apresentado por Rogers, Dearing e Bregman (1988. citados em Traquina, 2000), à agenda jornalística, à agenda da política governamental e à agenda pública. Na sua interface com a agenda jornalística, os news assemblers determinam quais são as notícias importantes, os news promotors estabelecem a agenda da política governamental e também são agentes especializados e membros do campo político, que ganham o direito de figurar na agenda jornalística, e os news consumers correspondem às pessoas sujeitas à influência das mídias e que vão ajudar a construir a agenda pública (Traquina, 2000, p. 20).

\section{O poder de agendar o cotidiano}

Alguns traços do que um século mais tarde seria o conceito de agendamento foram definidos pelo historiador do pensamento econômico alemão Karl Knies que sugeriu por volta de 1857 que, além de descrever os acontecimentos diários, as notícias podiam influenciar o poder de decisão dos leitores. Os leitores percebiam o mundo ao seu redor, dizia ele, em sintonia com o que era selecionado pelo jornalista. O jornalista, por sua vez, produzia o jornal conforme o gosto da massa dos leitores (citado em Hardt, 1979, p. 89 , 93). Havia, assim, um fluxo de influência mútua entre leitores e produtores e o interesse do povo atravessava o jornalismo embora isso não significasse nem uma paćronização entre os jornais nem uma submissão incondicional às necessidades do leitor. Os jornais, segundo Knies, criavam necessidades de consumo de mercadorias e de informação sobre a vida cotidiana e os "negócios públicos", assim como os leitores exigiam "sempre mais por menos dinheiro". Quase um século mais tarde, nos anos 20, Walter Lippman e Robert Park exploraram o mesmo tema. Em Public opinion, Lippmann (1921) sugeriu a existência de um vínculo estreito entre os jornais e o público, quando argumentou que a imprensa era a principal ligação entre os acontecimentos 
no mundo e as imagens de experiências privadas e expectativas estereotipadas ${ }^{9}$ existentes na mente do leitor. Nesta condição, a imprensa seria a fonte de produção de um tipo de conhecimento em relatos já ditos de outro modo ${ }^{10} \mathrm{e}$ que, para cair nas graças do leitor, dos políticos e das instituições, os jornais abordariam aquilo que o leitor acha que conhece - o seu trabalho, sua igreja, seu partido político -, ou manipulariam os acontecimentos; com isso a folha venderia mais e estaria imune às críticas violentas ${ }^{11}$. $O$ gosto popular não era muito diferente na metade do século XIX: religião, economia e negócios, dizia Knies, eram os temas mais abordados pelos jornais (citado em Hardt, 1979, p. 93).

Em "The natural history of the press", Robert Park (1923) concordaria em parte com Lippmann: os jornais de opinião norte-americanos dedicavamse a acontecimentos tão prosaicos como casamentos e divórcios, crimes e política. Mas Park diria, ainda, que desse modo a imprensa teria sido um elo com o público desde as primeiras manifestações em que os jornais eram um veículo para contar histórias e organizar boatos de vizinhança; na sequiência, - no final do século XIX, os jornais das metrópoles urbanas se dedicariam a reproduzir as condições de vida das pequenas comunidades. Os jornais decimonônicos precisavam vender para acompanhar os progressos do setor e os leitores, principalmente os imigrantes, desejavam encontrar na imprensa os referentes do seu cotidiano. Assim, ao publicar acontecimentos aparentemente tão prosaicos, os jornais estariam correspondendo a um desejo do público e, ao mesmo tempo, teriam incorporado e aperfeiçoado, ao longo da história, segundo Park, as formas ancestrais de controle social - boatos e falatórios - exercidas originalmente através da comunicação pessoal (1923, p. 278, R. Berganza, 2000, p. 237).

Knies, Park e Lippmann identificaram a tentacularização da imprensa nos limites da sociedade, da cidade, das instituições e do indivíduo. Park avançou igualmente em uma pragmática da comunicação cujo impacto residiria na notícia e no efeito de ressonância que essa provocava nos acontecimentos. Poder-se-ia identificar este poder "espontâneo" em duas etapas do processo comunicacional:

1. Na relação típica entre emissor/receptor. No século XVIII, ilustrou Park, os parlamentares ingleses teriam se dado conta de que não se dirigiam somente aos políticos, mas, indiretamente, através da notícia, quando falavam na tribuna, falavam à toda população $0^{13}$ (1923, p. 280). Em outro momento, referindo-se aos jornais modernos, Park daria mais consistência e precisão aos círculos de influência da comunicação, sugerindo que as notícias regulavam tanto as discussões de que se forma a opinião pública quanto o preço das mercadorias ou a influência persistente e penetrante da moda, e que esse poder se capilarizaria no espaço global ${ }^{14}$, com a multiplicação dos meios de comunicação: 
Mostrei o papel que a notícia desempenha no mundo da política na medida em que ministra fundamentos para as discussões de que se forma a opinião pública. A notícia representa papel importantíssimo no mundo das relações econômicas, visto que o preço das mercadorias. inclusive do dinheiro e dos valores, tal como se registra no mercado mundial e em todos os mercados locais que dele dependem, se baseia na notícia (1940, p. 183).

Park retomaria neste ponto de sua obra o pensamento de uma vertente das "social theories" aberta por Knies (1857) que se ocupou da publicidade como uma parte do jornal que se tornara o veículo mais importante para transmissão de mensagens comerciais e esta, além de ampliar a área geográfica das vendas para fora dos limites da vizinhança física, estimulava a competição e o consumo. economizava tempo e esforço dos compradores e uniformizava preços. Mais do que isso, a publicidade, dizia Knies. deveria ser utilizada como fonte de informações por historiadores e políticos que quisessem aprender mais sobre as condições sócio-econômicas das comunidades, cidades ou regiões (citado em Hardt, 1979, p. 87). Através da publicidade, dizia. os jornais eram instrumentos para o progresso da economia e dos negócios: através da distribuição das notícias sobre a vida pública a amplas áreas da população. participaram ativamente dos processos de amplificação das políticas oficiais e constituição do estado moderno. Small e Vincent (1894) acreditavam, como Knies, que os jornais precisavam ter sucesso econômico c agradar o público, mas que deviam 'conduzir o público positivamente mesmo tendo que se adaptar às suas opiniões. gostos e preconceitos' (citado em Hardt, 1979, p. 203).

Essa proximidade não cra bem vista por outra vertente das "social theories". Ross (1912) sugeriu que os grandes anunciantes podiam exercer simultaneamente a censura e a publicidade e o economista e jornalista alemão K. Bücher (1930) acreditava que a publicidade devia circular em um periódico especializado. Segundo Ross,

when news column and editorial pages are a mere incident in the profitable sale of meercantile publicity, it is strictly 'business-like' to let the great advertisers censor both (citado em Hardt. 1979. p. 210)

Bücher defendeu a criação de "folhas de publicidade" e que essas fossem controladas pela administração pública e queria uma imprensa independente e livre que representasse os interesses do povo. Bücher dizia que essa reforma era para acabar com o perigo de "subversão" da imprensa pelos interesses econômicos. Para ele, a publicidade não podia ficar sob a responsabilidade do setor privado: deveria passar para a guarda do estado 
como outros meios de transporte, estradas, o serviço postal ou telefonia. Segundo Bücher,

...advertising is a creation of transportation, like postal service, telephone and railroads and cannot be left in the hands of private concerns. The transfer of advertising to come under administration follows considerations similar to those of the last generation in connection with the naturalization of the railroads: it intends to protect the general interest which is tied to transportation (citado em Hardt, 1979, p. 114-115).

2. Os jornais agendam o cotidiano dos leitores. A 'notícia é qualquer coisa que faz as pessoas falarem' ${ }^{15}$, diria inicialmente Park, apoiando-se nas palavras do jornalista norte-americano Charles A. Dana ${ }^{16}$ para avançar, quase 20 anos depois, na composição da notícia com a noção de opinião pública: muito mais que informar o indivíduo sobre o que está acontecendo ao seu redor, as notícias orientam o público sobre os temas que se estão discutindo, podem fazer surgir o desejo coletivo, podem gerar um poder político e mobilizar uma comunidade. 'É este o poder da imprensa' ${ }^{17}$, diria Park. Neste sentido, a notícia e o jornal seriam igualmente instrumentos de agendamento e instrumentos de controle social que, à semelhança daqueles instrumentos ancestrais, já mencionados anteriormente, assinalam o que sai da normalidade, dando o que falar e preservando uma certa sanidade dos indivíduos, sanidade entendida como a condição de integração na sociedạde ou, nas palavras de Park, notícia e jornal são mecanismos normativos que tenderiam a manter os indivíduos 'dominados por um estado de espírito comum, que lhes determina o âmbito e o caráter dos interesses e atitudes ou tendências para agir' (1940, p. 181-183).

Isso não supõe 'nenhum esforço do jornalista para interpretar os acontecimentos exceto um modo de torná-los compreensíveis e interessantes' porque a notícia realiza para o público as mesmas funções que a percepção para o indivíduo, 'inteirando cada um e todos do que está acontecendo', a notícia define uma certa ordem de preferências temáticas, isto é, dirige a atenção do leitor que a percebe a determinados acontecimentos inesperados (1940, p. 176). Isso é o que Park chama 'a função indicadora das notícias ${ }^{18}$ '; Lippmann $^{19}$ já havia dito mais ou menos o mesmo: como os repórteres não podiam dar o seu testemunho a todos os acontecimentos, davam relevância aos que se destacavam mais e dirigiam para eles a atenção do público.

Por outro lado, retomando Park, a notícia para se concretizar como um instrumento de controle social e fundamento da opinião pública não depende da 'qualidade dos argumentos. O fator decisivo é qual dos lados em uma controvérsia tem fo:ça suficiente para ameaçar o lado contrário com o isolamento e o ostracismo formada com base nas notícias, ou seja, o fator decisivo na formação da opinião pública está na interpretaçãa da notícia por 
cada indivíduo, de acordo com os seus próprios interesses, preconceitos e predileções, que entra em jogo, na esfera da recepção, com a interpretação da mesma notícia por outros indivíduos. Lippmann já havia dito que o indivíduo define o mundo ao seu redor de acordo com estereótipos presentes em sua mente ${ }^{20}$ e que os jornais, agindo sobre o público por 30 minutos durante 24 horas, podiam criar uma "força mística" - a Opinião Pública ${ }^{21}$. Este papel de máquina da informação era assumido indevidamente pela imprensa. Para Lippmann, neste papel, os jornais preenchiam uma lacuna que deveria ser ocupada pelas instituições e com isso se transformavam em uma "Corte da Opinião Pública" aberta dia e noite e pronta para aplicar a lei a tudo e a toda hora e para produzir acontecimentos como um pacote de problemas, que a população era, então, chamada a resolver.

Em "Social Decadence", artigo publicado em 1918, Ross reconheceu que os jomais tinham 'um grande e crescente poder sobre o público' e sugeriu que isto acontecia porque noticiavam um tipo de fato, mantinham versões na clandestinidade, alçavam o que queriam à primeira página e com a relevância determinada por seu dono. Ou seja, o dono do jornal fazia a opinião pública sem que o público soubesse disso. Oito anos antes, Ross analisara a supressão das notícias importantes. 'As boas notícias. disse, estão sendo deliberadamente suprimidas ou distorcidas. Isso acontece agora com mais frequêencia e tudo indica que prosseguirá com maior frequêencia no futuro' (1994, p. 194).

\section{O processo de seleção dos acontecimentos}

Small e Vincent (1894) e K. Bücher (1915) esboçaram com agudeza a figura que ocuparia, mais tarde, o bojo do conceito de gatekeeper. Nela descreveram o editor de telégrafo, que recebia e selecionava o material produzido pelas agências de notícias nacionais e internacionais que, por sua vez, faziam chegar até os jornais os relatos dos correspondentes que mantinham em todo o mundo (citados em Hardt, 1979, p. 203). O editor, na visão de Small e Vincent, era uma conexão entre o jornal e o mundo:

The telegraph editor is the connecting link between the paper and the outside world. He reads the messages sent from the head office of the general press association, and selects such matter as he deems desirable. The general manager of this press service, sitting in his office in New York or Chicago, receives reports from his special correspondents in all parts or the country. These he sifts and then transmits to several central distributing points. whence they are telegriphed to the various papers in the association. Now and then, a cable message arrives from na international agency in London or Paris. where news from all 
over the world is being collected and distributed to meet the demands of different countries. Thus the report of na anarchist outrage in Seville finds a ready channel via Madrid; Paris, London, and New York or Chicago to any American city or large town (citado em Hardt, 1979, p. 200).

Bücher acreditava que esse mesmo editor, no comando do telégrafo, estava exposto à propaganda de guerra, aos interesses nacionais, de grupos de pressão ou "de seu patrão", e que, em sua posição de filtro do noticiário não levava nada disso em conta. Ao conduzir o processo de seleção, considerava as suas primeiras impressões que, não iam além de uma avaliação da veracidade do noticiário. As condições de produção das notícias não eram avaliadas. $\mathrm{E}$ assim, no controle do telégrafo, o editor suprimia as notícias que considerava desagradáveis dando importância às agradáveis. Essa atitude, que dava espaço no noticiário à exploração continuada de materiais que exploravam visões parciais e/ou distorcidas do que acontecia na realidade ("one-sided materials"), principalmente em época de guerra, poderia causar mais estragos na opinião pública do que um ataque armado em campo de batalha.

Knies ainda não havia relacionado a máquina com o poder das agências de notícias; refletiu separadamente sobre o telégrafo e o jornalista. A imprensa, dizia, ao contrário do que ocorria entre duas pessoas, introduziu um mensageiro na transmissão das mensagens e foi esse terceiro elemento que acabou abrindo os "portões" para os mal-entendidos, até a introdução dos sistemas técnicos, como o telégrafo, que deram uma dimensão impessoal ao processo (citado em Hardt, p. 80-82). Por outro lado, Knies sugeriu que o processo de seleção das notícias em outras condições, ou seja, sem a interferência do telégrafo e do noticiário produzido pelas agências internacionais, podia fornecer as pistas para descobrir como os jornalistas tentavam dirigir a atenção dos leitores privilegiando, dando tratamento diferenciado ou silenciando certos acontecimentos (citado em Hardt, p. 89).

Tönnies (1887) realizou um deslocamento do poder do sujeito para o sistema e ampliou a influência potencial da imprensa ao domínio mundializado. A imprensa, dizia, era uma força capaz de abolir a multiplicidade dos estados e substituí-los por um mercado único onde os meios de coerção seriam apenas de natureza psicológica.

In its tendencies and potentialities, is definitely international, thus comparable to the power of a permanent or temporary alliance of states. It can, therefore, be conceived as its ultimate aim to abolish the multiplicity of states and substitute for it a single.world marcket, which would dispense with means of coercion other than those of a psycological nature. Such tendencies and intentions will perhaps never find a clear expression, let alone realization, but their 
recognition serves to assist the understanding of many phenomena of the real world and to the realization of the fact that the existence of natural states is but a temporary limitation of the boundary - less Gesellschaft (citado em Hardt, p. 151).

Tönnies considerava a imprensa um "mercado impresso" (printed marketplace), que manipulava intencional ou involuntariamente os acontecimentos tanto nos períodos de guerra - se a propaganda determinava a tonalidade ao noticiário - como no mundo dos negócios, se a cobertura jonalística se articulava às atividades econômicas (citado em Hardt. p. 147).

Small e Vincent insistiram na crítica aos jornais e diziam que o progresso da empresa jornalística não tinha chegado na cobertura dos acontecimentos em que essa continuava "descuidada e ineficiente" como nos velhos tempos em que se dedicava às "fofocas impressas". A imprensa distorcia os fatos, não era um serviço adequado para relatá-los. Com isso. era praticamente impossível recolher dos jornais um conhecimento preciso sobre as atividades sociais e um verdadeiro sentido das atitudes éticas:

The press did not provide adequare services in reporting facts. giving directions to public opinion, and regarding form and contents of their information. Despite its highly organized character the press remained careless and inefficient in its news coverage: Small and Vincent felt that the "average nenspaper as a reporter of reality is the old-time gossip in print' (Hardt, p. 202).

\section{Os líderes de opinião}

Small e Vincent descrevem o papel dos líderes de opinião. que havia sido reconhecido anteriormente por Tönnies no conceito de "opinion leader" (citado em G. Marx, 2000: 3), antecipando o que mais tarde Lazarsfeld vai denominar "two step flow".

Essa figura, na concepção de Small e Vincent. era uma derivada de dois elementos - o crescimento da população e da circulação dos jornais - $\mathrm{e}$ do poder desses de controlar o público indiretamente. como o faziam os partidos, as igrejas e outras instituições que não controlavam somente os seus "círculos eleitorais" imediatos, mas geralmente atravessavam círculos mais amplos com o seu poder (citados em Hardt, 1979. p. 200).

Assim, a imprensa se tornara, no ponto de vista dos dois autores. o principal meio de comunicação das autoridades com os seus seguidores, como demonstravam os líderes tcológicos que possuíam os seus próprios jornais, os governantes e políticos que geralmente controlavam jornais pessoais e os partidos, facções, sindicatos que dirigiam os seus próprios órgãos ou exerciam influência sobre outros jornais. 
Na concepção de Bücher a imprensa era um dispositivo de transmissão de idéias entre o povo e os seus líderes que, ao longo de sua história tinha prestado esse serviço ora às administrações públicas, ora aos intelectuais. Os fluxos de poder, portanto, não estavam no interior dos jornais; os editores não eram independentes, eles apenas deixavam passar os impulsos intelectuais emanados, isso sim, dos centros culturais e políticos para que fossem divulgados às massas e, posteriormente, recolhiam as suas reações para reabastecer os centros do movimento intelectual:

The active, leading elements from whom those currents flow are found above, not inside the press. Editors and contributors do not fit into and independent, creative and leading role. They are organs of adaptation. Their work is primarily one of moulding. They forge the metal which is discovered by the creative, intellectual work in politics, science, art and technology into small coins so that it may be circulated. They disperse the intelectual impulses, which emanate from political and cultural centers, among the masses and collect their reactions to return them to the centers of the intellectual movement (citado em Hardt, p. 108).

Bücher (1926) retoma o pensamento de Schäffle (1881): a imprensa, dizia Schäffle, é a mais poderosa instituição social, um "super poder" que dá vazão às correntes intelectuais e possibilita o intercâmbio de idéias entre o povo e os seus líderes. Nessa condição, a imprensa encontra-se entre o governo e os partidos políticos, de um lado, e o público, de outro:

The most powerful means to influence public opinion by intellectually active elements. In this role the press is a super power. Belletristic literature, the tribunal, the forum, the eloquence of profane and sacred language, even the social conversations of salons, clubs and pubs as a psycho-phisical fondation of public opinion must yeld to the daily press and take up the second or third position (citado em Hardt, 1979, p. 64).

Alguns anos depois, Lasswell elaborou uma metáfora da sociedade animal $^{22}$ para descrever de outro modo as figuras do jornalista e dos líderes de opinião. O "sentinela", dizia, anuncia as novidades entre as coisas alarmantes que passam na realidade. Os "líderes especializados", a cada anúncio de mudança estimulam os "seguidores" a se adaptarem às novas circunstâncias anunciadas. Segundo Lasswell,

...en algunas sociedades animales, ciertos miembros desempeñan misiones especializadas y vigilan el entorno. Los individuos actúan como "centinelas", separados del rebaño o manada y creando un estado de alarma cada vez que ocurre un cambio alarmante en los 
alrededores. El trompeteo, cacareo o chillido del centinela basta para poner a todo el grupo en movimiento. Entre las actividades emprendidas por "lideres" especializados se cuenta la estimulación interna de "seguidores" para adaptarse ordenadamente a las circunstancias pregonadas por los centinelas (em Moragas Spa. 1985).

\section{Considerações finais}

O que está dito nestes discursos ilumina um modo "sociológico" de pensar e tratar o jornalismo e, mais concretamente, fornece pistas para que se possa entender melhor a formação do pensamento jornalístico e o fenômeno jornalístico em suas relações com a sociedade no momento de constituição do jornalismo como um dispositivo de poder capitalista. Ao mesmo tempo, esses discursos materializam a existência de uma rede conceptual que lhes dá fundamento e é formada por epistemes exógenas, que interligam diferentes saberes e que precedem a existência de um campo organizado do jornalismo. No lugar mesmo dessa heterogeneidade discursiva, em trabalho anterior visibilizamos as relações enunciativas, que permaneciam adormecidas no passado, entre esses teóricos e as mesmas práticas jornalísticas da época, embora entre uns e outros não pareça existir a mais mínima relação de dependencia. São esses mesmos discursos que se mostram no presente texto como continente do pensamento comunicacional contemporâneo. Acreditamos que tanto as "social theories of the press". como os discursos publicados pela imprensa brasileira decimonônica ou sobre ela, bem como o método arqueológico de aproximação ao conjunto de enunciados que pode ser reconstituído com base no sistema foucaultiano do arquivo, podem responder à necessidade apontada por Traquina de visibilizar através da investigação, que o "estudo do jornalismo constitui um campo científico com já longas tradições na comunidade acadêmica embora muitos jornalistas teimem em ignorar ou desprezar este "corpo teórico", satisfeitos com a sua 'lógica das mãos e dos olhos" (Lévi-Strauss, 1968, citado em Traquina. 2000).

\section{Referências bibliográficas}

BERGANZA CONDE, $M^{2}$. R. Comunicación, opinión pública y prensa en la sociología de Robert E. Park. Centro de Investigaciones Sociológicas, Madrid, 2000.

BREED, W., "Controle social na redação. Uma análise funcional." Em TRAQUINA, N. Jomalismo: questões, teorias e "estórias". Lisboa, Vega, 1993. 
BUCK-MORSS, S. Dialética de la mirada. Walter Benjamin y el proyecto de los Pasajes, La balsa de la Medusa, Madrid, 1995.

COHEN, E., McCOMBS, SHAW, D. "A função do agendamento dos media”, em TRAQUINA, N. O poder do jornalismo. Análise da teoria do agendamento. Coimbra, Minerva, 2000.

DELEUZE, G. Foucault. Barcelona, Paidós, 1987.

FOUCAULT, M. A arqueologia do saber. Rio de Janeiro, Forense Universitária, 1995.

HARDT, H. Social theories of the press. Early german \& american perspectives. Beverly Hills, Sage Publications, Inc., 1979.

LIMA BARRETO. Recordações do escrivão Isaías Caminha. São Paulo, Editora Brasiliense, 1956.

LIPPMANN, W. Liberty and the news, Transaction Publishers, New Jersey, 1995.

McCOMBS, M.E., SHAW, D. "A evolução da pesquisa sobre o agendamento: vinte e cinco anos no mercado das idéias." Em TRAQUINA, N. O poder do jornalismo. Análise da teoria do agendamento. Coimbra, Minerva, 2000.

MAROCCO, B. Prostitutas, jogadores, pobres e vagabundos no discurso jornalístico, Editora Unisinos, São Leopoldo, 2004.

80 opinion." Em web.mit.edu/gtmarx/www/tonnies.html/

MORAGAS SPÁ, M. Sociología de la comunicación de masas, tomo II, Gustavo Gilli, Barcelona, 1985.

NIEVAS, F. El control social de los cuerpos. Buenos Aires, Eudeba, 1998.

PARK, R. "Natural history of the newspaper". Em The American Journal of Sociology, Chicago, The University of Chicago Press, Volume 29, Issue 3 (Nov., 1923).

PARK, R. "News as a form of knowledge". Em The American Journal of Sociology, Chicago, The University of Chicago Press, Volume 45, Issue 5 (Mar., 1940).

RESENDE, B. Lima Barreto e o Rio de Janeiro em fragmentos. Rio de Janeiro, Editora UFRJ, 1993.

ROSS, E. "La supresión de las noticias importantes."Em Reis, Madrid, 1994/01

TRAQUINA, N. O poder do jornalismo. Análise e textos da Teoria do Agendamento. Coimbra, Minerva, 2000.

WHITE, D. M. "O gatekeeper. Uma análise de caso na seleção de notícias." Em TRAQUINA, N. (org). Jornalismo: questões, teorias e "estória". Lisboa, Veja, 1993. 
YARROS. V.S. "A neglected opportunity and duty in journalism." Em The american journal of sociology, Chicago, 1916, vol.1, no 1 .

\section{Notas}

' Aqui estão materializados parte dos resultados da pesquisa "Jornalismo e sociedade. As teorias sociais da imprensa" realizada com tempo disponibilizado para pesquisa acadêmica (dezesseis horas semanais) pela Unisinos no segundo semestre de 2003 e primeiro semestre de 2004. "As relações enunciativas materializam o "sistema de funcionamento" do arquivo que permite que os enunciados subsistam e se modifiquem regularmente. Assim, o arquivo é tanto o lugar do que pôde ser dito, como o nível particular das práticas discursivas dos saberes e das instituições que, no presente, vai possibilitar a atualização dos discursos do passado como práticas especificadas.

"Consideramos epistemes exógenas as teorias reunidas por H. Hardt (19\%9) no seio das "social theories": o grupo de pensadores alemães e norte-americanos formado por Albert Schäffle, Karl Knies, Karl Bücher, Ferdinand Tönnies, Max Weber, Albion Small, Edward Ross e Willian Sunmer. Nosso foco sobre a constituição do pensamento jornalístico e dos conceitos de agendamento e gatekeeper nos levou a aproximá-los no sistema do arquivo de teóricos como Robert Park e Walter Lippmann, que igualmente estudaram o jornalismo como um fenômeno social e transitaram entre os seus limiares de epistemologização e cientificidade. ${ }^{7}$ Segundo Cohen, embora a imprensa, 'na maior parte das vezes, possa não ser bem sucedida ao indicar às pessoas como pensar, é espantosamente eficaz ao dizer aos seus leitores sobre o que pensar' (citado por McCombs e Shaw, em Traquina, 2000, p. 49)

${ }^{*} \mathrm{O}$ estudo foi realizado durante as eleições presidenciais norteamericanas de 1968 e baseou-se em entrevistas com uma amostra de 100 eleitores indecisos de Chapell Hill e na análise de conteúdo de informação política divulgada por jornais, rádios e emissoras de TV que cobriam os cinco distritos eleitorais abrangidos.

"Disse Lippmann: 'These customers deliver judgment according to their private experiences and their stereotyped expectations, for in the nature of things they have no independent knowledge of most news the read' (1921, part VII Newspaper - Chapter XXII The constant reader - 2)

10 Disse Lippmann: 'This, then, will be the clue to our inquiry. We shall assume that what each man does is based not on direct and certain knowledge, but on pictures made by himself or given to him. If his atlas 
tells him that the world is flat he will not sail near what he believes to be the edge of our planet for fear of falling off. If his maps include a fountain of eternal youth, a Ponce de Leon will go in quest of it. If someone digs up yellow dirt that looks like gold, he will for a time act exactly as if he had found gold. The way in which the world is imagined determines at any particular moment what men will do. It does not determine what they will achieve' (1921, part VII Newspaper - Chapter XXII The constant reader -1$)$.

${ }^{11}$ Disse Lippmann: 'If the newspaper gives a satisfactory account of that which we think we know, our business, our church, our party, it is fairly certain to be imune from violent criticism by us' (1921, part VII Newspaper - Chapter XXII The constant reader - 1).

${ }^{12}$ Disse Park: 'O fato de que a notícia costuma circular espontaneamente e sem quaisquer ajudas adventícias - além de circular livremente, sem inibições nem censuras - parece ser responsável por outro caráter que a ela se prende, estremando-a de tipos correlatos, porém menos autênticos de conhecimento - a saber, o boato e o falatório' (1940, p. 177).

${ }^{13}$ Disse Park: 'As soon as the parliamentary orators discovered that they were adressing not only their fellows-members but, indirectly, through the medium of the press, the people of England; the whole character of parliamentary proceedings changed. Through the newspapers the whole country was enabled to participate in the discussions by which issues were framed and legislation was enacted' (1923, p. 280).

${ }^{14}$ Disse Park: 'De fato, a multiplicação dos meios de comunicação permite agora a qualquer pessoa, ainda que se encontre na região mais afastada do mundo, participar realmente dos acontecimentos - se não como espectador, ao menos como ouvinte - na medida em que se verificam em outra parte do globo" (1940, p. 184). Essa questão, que voltaria a abordar em The city and civilization (1936), mostra que Park já havia percebido dois fenômenos extremamente atuais: a "sociedade de informação" e a globalização das relações sociais: "Las fuerzas que controlan los destinos del mundo [...] tienen que ver com el mercado monetario internacional y com las noticias internacionales. En tanto esto es verdad, estos poderes están en gran medida concentrados en cuatro o cinco ciudades, quizás, al final, en una' (citado por B. Conde, 2000, p. 242).

${ }^{15}$ Disse Park: 'What is news? There have been many answers. I think it was Charles A. Dana, who said, 'News is anything that will make people talk'. This definition suggests at any rate the aims of the new journalism. Its purpose was to print anything that would make people 
talk na think, for most people do noot think until they begin to talk' (1923, p. 285).

${ }^{16}$ O clássico epigrama da Teoria da Informação, 'Um cachorro que morde um homem não ć notícia, mas um homem que morde um cachorro é notícia', raramente atribuída a Dana, parece ilustrar a idéia desse jornalista.

${ }^{17}$ Disse Park: 'The role of the press in this situation is obviously not merely to orient the public in regard to the issues involved but to bring into existence a collective will and a political power which, as it mobilizes the community to act, tends to terminate discussion. It is this that constitutes the power of the press' (1941).

${ }^{18} \mathrm{M}$. McCombs e D. Evatt situam esta função na origem da agenda-setting embora atribuam a Lippmann o fundamento intelectual da mesma, o que, na opinião de B. Conde, deve-se à precária divulgação da obra de Park. 'En mi opinión, diz ela, a Park sólo se le menciona tímidamente como precursor de esta teoría porque su obra es muy poco conocida. De ahí que las referencias a su aportación intelectual en este contexto sean. cuando existen, muy breves y carezcan totalmente de justificación. La alusión y explicación de las contribuciones de Lippmann. cuya obra ha sido más difundida, es, sin embargo, mucho más amplia' (B. Conde, 2000 , p. 270)

${ }^{19}$ Nas palavras de Lippmann, "as notícias não nos dizem como germina a semente na terra. mas podem dizer quando aparece na superfície o primeiro broto' (citado por B. Conde. 2000, p. 270).

${ }^{20}$ Disse Lippmann: 'We do not first see, and then define, we define first and then see'. Em outras palavras. segundo Lippmann. 'we define the world around us according to prexisting stereotypes' (1921, part III Stereotypes - Chapter VI Stereotypes).

${ }^{21}$ Disse Lippmann: 'Acting upon everybody for thirty minutes in twentyfour hours, the press is asked 10 create a mystical force called Public Opinion that will take up the slack in public institutions. The press has often mistakenly pretended that it could do just that. It has at great moral cost to itself, encouraged a democracy, still bound to its original premises. to expect newspapers to supply spontaneously for every organ of government, for every social problem, the machinery of information which these do not normally supply themselves. Institutions having failed to furnish themselves with instruments of knowledge, have become a bundle of 'problems' wich the population as a whole. reading the press as a whole, is supposed to solve' (1921, part VII Newspaper - Chapter XXIV News, Truth and a conclusion).

22 'Los procesos de comunicación de la sociedad humana, segundo Lasswell, una vez examinados detalladamente, revelan numerosas 
equivalencias con las funciones especializadas que se encuentran en el organismo físico y en las sociedades animales inferiores' (em Moragas Spá; 1985).

84 